\title{
Barriers to Health Care for Disabled People: A Review of the Literature from Low Income Countries
}

\author{
Brian Chanda Chiluba
}

The University of Zambia, School of Health Sciences, Epidemiology \& Biostatistics Unit

\begin{abstract}
Over the years, they have been suggestions that people with disabilities face barriers when accessing health care services unlike their abled counter-parts. However, information regarding the nature of these barriers, especially for those in low income and middle income countries is not abundant and very sparse. signing of the United Nations Convention on the Rights of Persons with Disabilities on May 3, 2008 is one of the most important disability actions taken to date which marked national recognition of the rights for persons with disabilities, of which included access. The studies explored in this article review issues related to access to health care and those mostly used in areas within the Sub-Saharan as their sample site. The following document contains published studies that determine if disability limits access to health care and to attempt to identify what contextual factors (environmental and personal factors), interact with to limit this access. The findings were that people with disability who came from rural areas did find it harder to access healthcare than their urban counterparts. The major reason behind this is transportation from home to the health facility. A number of other reasons were also considered, such as no services were available.
\end{abstract}

Keywords: Disability; Health care; Low income; Barriers

\section{Introduction}

Reading skills have an important role in human life. Reading is one of four language skills (listening, speaking, reading, and writing skills) that must be learned by children in the school (Tarigan, 2008: 1). In this case, reading can be interpreted to understand the written text by reading inwardly or reciting written texts orally.

The United Nation's Convention on the Rights of Persons with Disabilities (UNCRPD) is a human rights instrument intended to protect persons with disabilities' dignity and rights. Eight guiding principles underlie the Convention, of which accessibility is one of them" (WHO, 2011).

Compromised access to health care is a major issue of discussion worldwide. Health care needs that are not met and that exacerbate health disparities are experienced disproportionately by persons with disabilities

* Corresponding author: Brian Chanda Chiluba

brian.chiluba@unza.zm

Published online at http://IJDS.ub.ac.id/

Copyright @ 2019PSLD UB Publishing. All Rights Reserved
(Leonardi et al, 2006). Inequity in accessing health care for persons with disabilities is a global issue - in general, persons with disabilities have poorer health care access" (Bickenbach et al, 1999). It has been said that political marginalisation, as well as discrimination and inequitable access to health services are experienced by persons with disabilities resulting in poorer health outcomes.

\section{Challenges to Access of Healthcare by Persons Living with Disability}

The majority of individuals with disability live in low-income contexts (Ustun et al, 2003). Recently, there has been an accumulation of evidence that barriers to health care access exist for persons with disabilities in less resourced countries (Madans et al, 2011). Marella, Busija et al says access to health care, even in wealthy countries, is often difficult for persons with disabilities, but in poorer countries the challenges are even more, combining physical, financial, resource and attitudinal components (Marella et al, 2014).

Concern over the availability of health services in rural areas has existed for decades 
and "rural communities have long struggled to maintain access to quality health care services" (Ustun et al, 2003; Trani et al, 2015). With that being said, primary care must not just be available in the rural areas, it must also be accessible by the public, especially those disabled. One would expect that rural populations have reduced access to health care services compared to their urban counterparts, but according to Madans, Loeb and Altman [5] studies have been contradictory and inconclusive.

Jeon, Kwon and Kim "show that persons living in rural and remote areas face multiple challenges in accessing appropriate health services (Jeon et al, 2015). Rural communities share certain characteristics that affect both health and health care, examples of such characteristics include; poor health infrastructure, high prevalence of chronic illnesses and disability, socioeconomic hardships and physical barriers such as distance and availability/lack of transportation" (WHO, 2011). Therefore, those in rural areas have to do without some services that those in the urban environments.

There is scarce data on disability and health care among the poor rural populations and their needs. What little literature there is suggests that persons with disabilities in rural areas have more problems and issues regarding their health care than persons with no disabilities in rural areas - especially when it comes to health care access (WHO, 2011).

The right to access health care services is guaranteed by the United Nations Convention on the Rights of Persons with Disabilities (UN CRPD) of 2008 (WHO, 2011). However, considerable inequities still remain and largely due to discrepancies in resource allocation ${ }^{[5]}$. In their study on access to health care in South Africa, Mactaggart et al. concurs with previous South Africa studies, confirming that poor, uninsured, Black Africans and rural groups have poorer access to health care than do other members of South African society (Mactaggart et al, 2016). Only a few studies have looked at disability issues in rural areas but these studies focused specifically on disability and access to health care. More on a large scale quantitative research contribute to assessing and improving access to health care for persons with disabilities needs to be prioritised - especially in Sub Saharan rural areas(Marella et al, 2016).
The aim of the study undertaken by Vergunst was to compare persons with disabilities and persons with no disabilities in terms of access to health care in a rural impoverished area in South Africa (Vergunst et al, 2017). While international literature brings support to the existence of access barriers and inequitable health services, evidence is still limited when it comes to equal access for persons with disabilities.

The hypothesis is that persons with disabilities have poorer access to health care in a rural impoverished area in South Africa.

Among people with disabilities, women with disability are a special group as they have additional sexual and reproductive health needs and prenatal, natal, and post-natal care needs compared to other segments of the population. A study from India showed that a significantly lower proportion of women with disability experienced pregnancy (36.8\%) compared to women without a disability (X2 -16.02; p < 0.001) (Madans et al, 2011). The study also observed that there were no statistically significant differences between women with and without a disability with regard to utilization of antenatal care and pregnancy outcomes (Madans et al, 2011). Similar observations have been reported from highincome countries also.

A study conducted in Rwanda on the health outcomes of persons with disability (PWD). Data on the health status, risk of disease and health outcomes of people with disabilities were compared with those without a disability (Table 1). Available evidence clearly indicates that the health needs of PWD were significantly more than those without a reported disability in Rwanda. Respondents with disability also reported significantly more unmet needs compared to those without a disability. In South Africa, it was observed that PWD visited health centers more often than those without a disability and the out-of-pocket expenses for PWD were higher (Vergunst et al, 2017). A study from Uganda observed that PWD were 14 times more likely than others to seek treatment (Ustun et al, 2003). 
Table 1. Health Outcomes in Persons with Disability.

\begin{tabular}{lll}
\hline Parameter & $\begin{array}{l}\text { People } \\
\text { with } \\
\text { Disability }\end{array}$ & No \\
& & Disability Remarks
\end{tabular}

\begin{tabular}{llll}
\hline $\begin{array}{l}\text { Ever } \\
\text { hospitalized }\end{array}$ & $17.8 \%$ & $5.0 \%$ & $p<0.001$ \\
$\begin{array}{l}\text { Current } \\
\text { medication }\end{array}$ & $9.4 \%$ & $5.1 \%$ & $p<0.001$ \\
$\begin{array}{l}\text { Known } \\
\text { diabetic }\end{array}$ & $12.5 \%$ & $0.7 \%$ & $p<0.001$ \\
$\begin{array}{l}\text { Feel low } \\
\text { constantly } 20.7 \%\end{array}$ & $2.4 \%$ & $p<0.001$
\end{tabular}

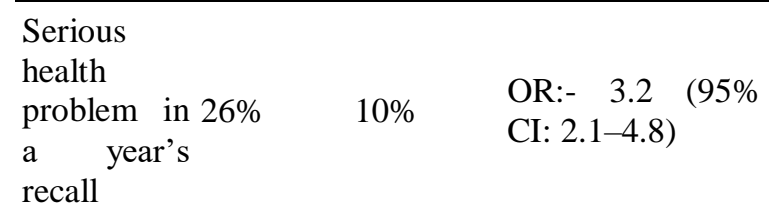

$\begin{array}{llll}\begin{array}{l}\text { Elevated } \\ \text { blood } \\ \text { pressure }\end{array} & 11 \% & 5 \% & \begin{array}{l}\text { OR: } 1.8(95 \% \text { CI: } \\ 1.0-3.3)\end{array} \\ & & & \\ \text { Diabetes } & 5 \% & 3 \% & \begin{array}{l}\text { OR: } 1.5(95 \% \text { CI: } \\ 0.7-3.3)\end{array}\end{array}$

\begin{tabular}{|c|c|c|}
\hline $\begin{array}{l}\text { Unmet } \\
\text { health need } 45.9 \% \\
\text { (South } \\
\text { India) }\end{array}$ & $26.8 \%$ & $p<0.001$ \\
\hline $\begin{array}{l}\text { Feel in } \\
\text { good health } \\
\text { most of the } 32.9 \% \\
\text { time (South } \\
\text { India) }\end{array}$ & $41.1 \%$ & $p<0.001$ \\
\hline $\begin{array}{l}\text { Unmet } \\
\text { health need } 29.7 \% \\
\text { (North } \\
\text { India) }\end{array}$ & $6.4 \%$ & $\begin{array}{l}\text { OR: } 5.5(95 \% \mathrm{CI} \\
2.7-11.3)\end{array}$ \\
\hline $\begin{array}{l}\text { Unmet } \\
\text { health need } 46.7 \% \\
\text { (East India) }\end{array}$ & $14.5 \%$ & $p<0.001$ \\
\hline $\begin{array}{l}\text { Feel in } \\
\text { good health } \\
\text { most of the } 27.8 \% \\
\text { time (South } \\
\text { India) }\end{array}$ & $60.2 \%$ & $p<0.001$ \\
\hline
\end{tabular}

Studies from Uganda showed that the prevalence of non-communicable diseases (NCDs) such as diabetes and hypertension were significantly higher among persons with disability (Murthy et al , 2014). Similar findings were reported from other parts of Sub Saharan Africa South Africa) too (Murthy et al , 2014). Physical impairments constitute a high proportion of PWD and with a sedentary lifestyle; risk of NCDs among these population subgroups will be high. This high risk of NCDs escaped attention earlier but with an increasing emphasis on these diseases and the flagging of the control of NCDs by the United Nations as part of the Sustainable Development Goals (SDGs), it is important to target PWD as a high-risk group for NCDs and SDGs in the future (Vergunst et al, 2017). This realization needs to be supported with uninterrupted medical supplies to ensure that the health of PWD is promoted (WHO, 2011).

In Figure. 1, the combined figures for "serious problems" and "insurmountable problems" are shown for both persons with and without disabilities. For all 18 items, more persons with than without disabilities report that the respective items are reasons for serious or insurmountable problems in accessing health care services

\section{Figure. 1}

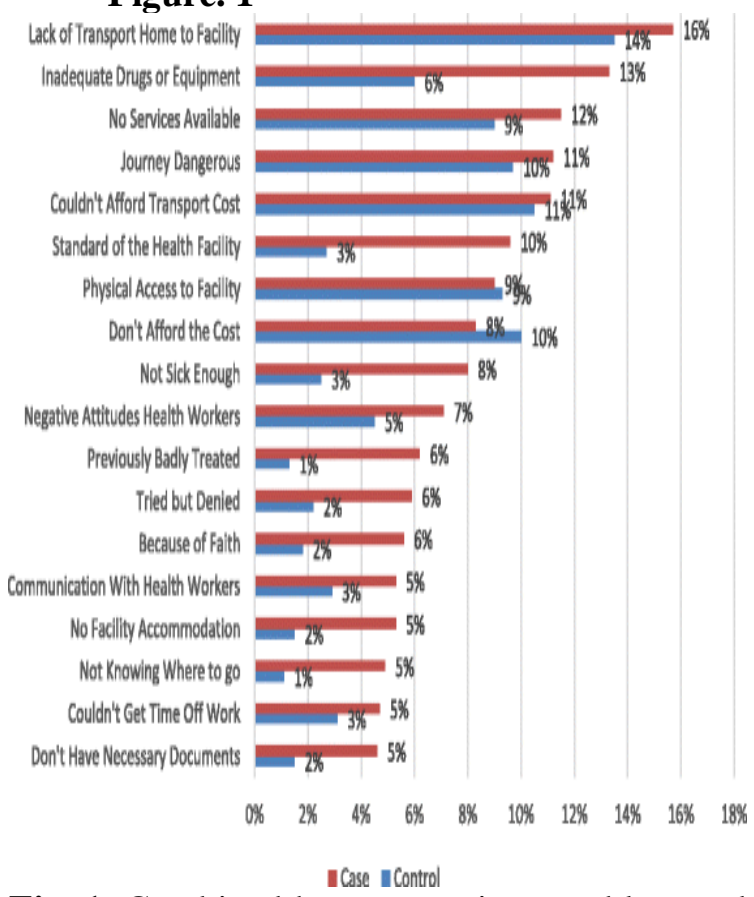

Fig. 1. Combined between serious problem and insurmountable problem

(Source: World Disability Report, 2016)

Cite this as:

Chiluba, Brian Chanda. Barriers to Health Care for Disabled People: A Review of the Literature from Low Income Countries. Indonesian Journal of Disability Studies (IJDS).2019: Vol. 6(2): PP 210 - 214. 
The above Fig 1. Shows that majority of the disabled did not access healthcare due to lack of transport from home to facility. The next reason is that the health facility had inadequate drugs or equipment. From the diagram, it is clear that the care is bigger than the control.

\section{Discussion}

Based on the results of the study, the conclusion is interactive multimedia has an influence on the loud reading skills in english subjects for the child with mental on $7^{\mathrm{TH}}$ grade of SLB Panca Bakti Mulia Surakarta in the academic year of 2018/2019.

\section{References}

World Health Organization. World Report on Disability. Who Press; Geneva, Switzerland: 2011. pp. 1-24.

Leonardi M., Bickenbach J., Ustun T.B., Kostanjsek N., Chatterji C. The definition of disability: What is in a name? Lancet. 2006; 19-21.

Bickenbach J.E., Chatterji C., Badley E.M., Ustun T.B. Models of disablement, universalism and the international classification of impairments, disabilities and handicaps. Soc. Sci. Med. 1999; 73-87.

Ustun T.B., Chatterji C., Bickenbach J., Kostanjsek N., Schneider M. The International Classification of Functioning, Disability and Health: A new tool for understanding disability and health. Disabil. Rehabil. 2003; 25:26

Madans J.H., Loeb M.E., Altman B.A. Measuring disability and monitoring the UN Convenetion on the Rights of Persons with Disabilities: The work of the Washington Group on Disability Statistics. BMC Public Health. 2011; 11

Marella M., Busija L., Islam F.M., Devine A., T.J., Huq N.L., Cama A., et al. Field-testing of the rapid assessment of disability questionnaire. BMC Public Health. 2014; 14:17.

Trani J.F., Babulal G.M., Bakhshi P. Development and validation of the 34-Item Disability Screening Questionnaire (DSQ-34) for use in low and middle income countries epidemiological and development surveys. 2015:10

Devine A., Armecin G.F., Zayas J. A rapid assessment of Disability in Rwanda. Understanding prevalence, well-being and access to the community for people with disabilities to inform the W-WARE Project. Pop. Health Metre. 14-26

Gulley S.P., Rasch E.K., Chan L. The Complex Web of Health: Relationships among chronic conditions, disability and health services. Public Health Rep. 2011; 49-50

Jeon B., Kwon S., Kim H. Health care utilization by people with disabilities: A longitudinal analysis of the Korea Welfare Panel Study (KpWePS) Disab. Health. 2015; 53

Mactaggart I., Kuper H., Murthy G.V., Oye J., Polack S. Measuring disability in population based surveys: The interrelationship between clinical impairments and reported functional limitations in Cameroon and India. PLoS ONE. 2016: 16

Marella M., Devine A., Armecin G.F., Zayas J., Marco M.J., Vaughan C. Rapid assessment of disability in the Philippines: Understanding prevalence, well-being, and access to the community for people with disabilities to inform the W.-DARE project. Pop. Health Metr. 2016; 14:26.

R. Vergunst, L. Swartz, K.-G. Hem, A. H. Eide, H. Mannan, M. MacLachlan, G. Mji, S. H. Braathen \& M. Schneider. Access to health care for persons with disabilities in rural South Africa BMC Health Services Researchvolume 17, Article number: 41 (2017)

Murthy G.V.S., John N., Sagar J., South India Disability Evidence Study Group Reproductive health of women with and without disabilities in South Africa, the SADE study (South Africa Disability Evidence) Study: a case control study. BMC Women's Health. 2014; 14

Senghor D.B., Diop O., Sombie I. Analysis of the impact of healthcare support initiatives for physically disabled people on their access to care in the city of Saint-Loius, Senegal. BMC Health Serv. Res. 2017; 17

Cite this as: 
Brian Chiluba, Esther Munalula-Nkandu, Chola Nakazwe Daka, Mumbi Chola, Gershom Chongwe, Cardiovascular Disease Risk from Protease Inhibitors-ART for HIV: Retrospective Cohort of University Teaching Hospital, Zambia, Cardiology and Cardiovascular Research. Vol. 1, No. 4, 2017,pp.98-103.doi: 10.11648/j.ccr.20170104.

11
Brian Chanda Chiluba and Wana Gift Njapawu. Barriers Of Persons With Physical Disability over Accessibility and Mobility to Public Buildings in Zambia.Indonesian Journal of Disability Studies (IJDS).2019: Vol. 6(1): PP $53-63$. 